\title{
Microvascular effects of intravenous esmolol in patients with normal cardiac function undergoing postoperative atrial fibrillation: a prospective pilot study in cardiothoracic surgery
}

William Fornier ${ }^{1,2,4^{*}}$ (D), Matthias Jacquet-Lagrèze ${ }^{1}$, Thomas Collenot ${ }^{1}$, Priscilla Teixeira ${ }^{1}$, Philippe Portran ${ }^{1}$, Rémi Schweizer ${ }^{1}$, Michel Ovize ${ }^{2,3}$ and Jean-Luc Fellahi ${ }^{1,2}$

\begin{abstract}
Background: Postoperative atrial fibrillation (POAF) is commonplace after cardiothoracic surgery. A rate control strategy using short-acting beta blockers is recommended as a first-line therapy in patients without hemodynamic instability. Microcirculatory effects of POAF and esmolol have not yet been investigated. We hypothesized that POAF without hemodynamic instability would induce microvascular dysfunction which could be reversed by intravenous esmolol.

Methods: Twenty-five cardiothoracic surgical patients with POAF were included in the study. Microcirculation was assessed by peripheral near-infrared spectroscopy (NIRS) in association with a vascular occlusion test (VOT) before esmolol infusion, during incremental doses of esmolol $(25,50,100$, and $200 \mu \mathrm{g} / \mathrm{kg} / \mathrm{min})$, and after a return to sinus rhythm. Esmolol was given to control heart rate to between 60 and 90 beats/min. Regional tissue oxygen saturation variables $\left(\mathrm{StO}_{2}, \mathrm{StO}_{2}\right.$ min, $\mathrm{StO}_{2} \max$, and $\left.\Delta \mathrm{StO}_{2}\right)$ and desaturation/resaturation speeds during VOT were recorded to evaluate the microcirculation.

Results: $\mathrm{StO}_{2}$ and resaturation speed were significantly improved when POAF returned to sinus rhythm $\left(\mathrm{StO}_{2} 64 \% \pm 6\right.$ versus $67 \% \pm 6, P<0.01$; resaturation speed $0.53 \% / \mathrm{s}(0.42-0.97)$ versus $0.66 \% / \mathrm{s}(0.51-1.04), P=0.020) . \Delta \mathrm{StO}_{2}$ was significantly decreased after a return to sinus rhythm $(7.9 \% \pm 4.8$ versus $6.1 \% \pm 4.7, P=0.026)$. During esmolol infusion, we found a significant decrease in both heart rate $(P<0.001)$ and blood pressure $(P<0.001)$, and a non-significant dose-dependent increase in $\mathrm{StO}_{2}(P=0.081)$ and resaturation speed $(P=0.087)$.
\end{abstract}

Conclusion: POAF without hemodynamic instability is associated with significant impairment in the microcirculation which could be partially reversed by intravenous esmolol.

Keywords: Regional oxygen saturation, Postoperative atrial fibrillation, Microcirculation, Near-infrared spectroscopy, Esmolol, Beta blocker

\footnotetext{
* Correspondence: w_fornier@yahoo.fr

${ }^{1}$ Department of Anesthesiology and Intensive Care Medicine, University Hospital Louis Pradel, Lyon, France

${ }^{2}$ Inserm U1060, IHU OPERA, Faculty of Medicine, Claude Bernard Lyon 1

University, Lyon, France

Full list of author information is available at the end of the article
} 


\section{Background}

Postoperative atrial fibrillation (POAF) is commonplace after cardiothoracic surgery [1], leading to an increase in mortality, morbidity, length of stay in hospital, and health costs $[2,3]$. When POAF is not associated with hemodynamic instability, a ventricular rate control strategy using beta blockers is recommended [4]. Intravenous esmolol is a short-acting cardioselective beta-1 blocker which has been proposed for POAF treatment $[5,6]$. Interestingly, the microcirculatory effects of both POAF and intravenous esmolol have not yet been investigated in this specific setting.

Near-infrared spectroscopy (NIRS) is a noninvasive, continuous, and readily available technology to assess microcirculation at the regional level [7-13]. Measurement of tissue oxygen saturation $\left(\mathrm{StO}_{2}\right)$ is determined by the difference in intensity between a transmitted and received light delivered at a specific wavelength, as described by the Beer-Lambert law. $\mathrm{StO}_{2}$ can be considered as a meta-parameter that reflects the regional balance between oxygen consumption and delivery. In addition, a vascular occlusion test (VOT) can be performed to assess the recruitment of microvessels in response to a local hypoxic stimulus by computing $\mathrm{StO}_{2}$ resaturation speed. A decrease in $\mathrm{StO}_{2}$ resaturation speed has been reported during hypovolemia, hemorrhagic shock, sepsis, and also following cardiac surgery [14-21]. During septic shock, the use of intravenous esmolol has been found to improve the microcirculation despite negative effects on macrocirculation parameters [22, 23].

Therefore, the aims of this prospective pilot study conducted in conventional cardiothoracic surgery were: 1 ) to assess the effects of POAF without hemodynamic instability on the microcirculation by means of peripheral NIRS in combination with a VOT; and 2) to investigate the dose-dependent effect of intravenous esmolol on the microcirculation in this setting. We tested the hypothesis that POAF would induce microvascular dysfunction which could be reversed by intravenous esmolol.

\section{Methods}

\section{Patients}

This prospective, single-center, observational study was conducted at the University Hospital Louis Pradel (Lyon, France) from December 2015 to September 2016 following approval by the Ethics Committee (A14-D06-VOL.20, 28/01/14, Comité de Protection des Personnes, Nord-Ouest 3; Committee Chair: Dr. Charlotte Gourio). The institutional review board waived written informed consent as no intervention was required. Verbal information was, however, given to all patients. We included adult patients scheduled for conventional cardiac or thoracic surgery who experienced inhospital POAF within the first 7 postoperative days. POAF was diagnosed on a 12-lead electrocardiogram and further considered if lasting at least $15 \mathrm{~min}$ after a Ringer lactate fluid challenge (3 $\mathrm{ml} / \mathrm{kg}$ ), and in the absence of significant dyskaliemia and/or hypoxemia. Patients with POAF leading to hemodynamic instability (hypotension defined as mean arterial pressure $<60 \mathrm{mmHg}$ ), usual esmolol contraindications, non-agreement, or permanent atrial fibrillation were not included into the study.

\section{Hemodynamic and NIRS monitoring}

At the time of the study, all patients were monitored with a five-lead electrocardiogram with computerized analysis of repolarization and invasive or non-invasive arterial blood pressure. After rubbing and cleaning the skin with an alcohol swab, a NIRS optode (O3 Sensor, Masimo Incorporation, Irvine, CA, USA) was carefully applied to the medial surface of the left or right forearm, $5 \mathrm{~cm}$ below the elbow. The sensor was attached to the skin of participants with opaque adhesive stickers so that the angle and position of the optode was kept constant. The sensor was connected to the four-wavelength $\mathrm{O} 3$ Regional Oximetry device (Masimo Incorporation). This device provides high accuracy for absolute $\mathrm{StO}_{2}$ values thanks to its four-wavelength sensor [24]. All $\mathrm{StO}_{2}$ values were recorded continuously and read every second. Data were recorded online, transferred to a laptop with a specific software designed by Masimo (Masimo Instrument Configuration Tool, MICT Version 1.0.4.9), and stored for further analysis. An automated pneumatic cuff inflator (Spengler SAS, Antony, France) was positioned at the upper extremity of the ipsilateral upper limb. After completion of a baseline set of measurements for each patient, a rapid arterial occlusion of the upper limb was provoked by inflation of the pneumatic cuff at $50 \mathrm{mmHg}$ above the systolic arterial pressure, until either the $\mathrm{StO}_{2}$ value decreases to $40 \%$ or for a maximal period of $10 \mathrm{~min}$. The arterial cuff was then rapidly deflated to initiate reperfusion. Finally, the measurement was repeated after $10 \mathrm{~min}$ of reperfusion (Fig. 1). During the whole study period, oxygen intake was kept constant and no hemodynamic intervention was performed. At each step the heart rate, blood pressure, and arterial oxygen saturation $\left(\mathrm{SpO}_{2}\right)$ were measured. Relevant NIRS parameters were baseline $\mathrm{StO}_{2}$, the minimal value of $\mathrm{StO}_{2}$ reached during ischemia $\left(\mathrm{StO}_{2} \mathrm{~min}\right)$, the peak value of $\mathrm{StO}_{2}$ during reperfusion $\left(\mathrm{StO}_{2} \mathrm{max}\right)$, the desaturation speed during ischemia $\left(\mathrm{StO}_{2}\right.$ baseline $-\mathrm{StO}_{2} \mathrm{~min} /$ time of ischemia), the resaturation speed during reperfusion $\left(\mathrm{StO}_{2} \max -\mathrm{StO}_{2}\right.$ $\mathrm{min} /$ time of reperfusion), and the variation in $\mathrm{StO}_{2}$ during reperfusion $\left(\Delta \mathrm{StO}_{2}=\mathrm{StO}_{2} \max -\mathrm{StO}_{2}\right.$ baseline $)$. 


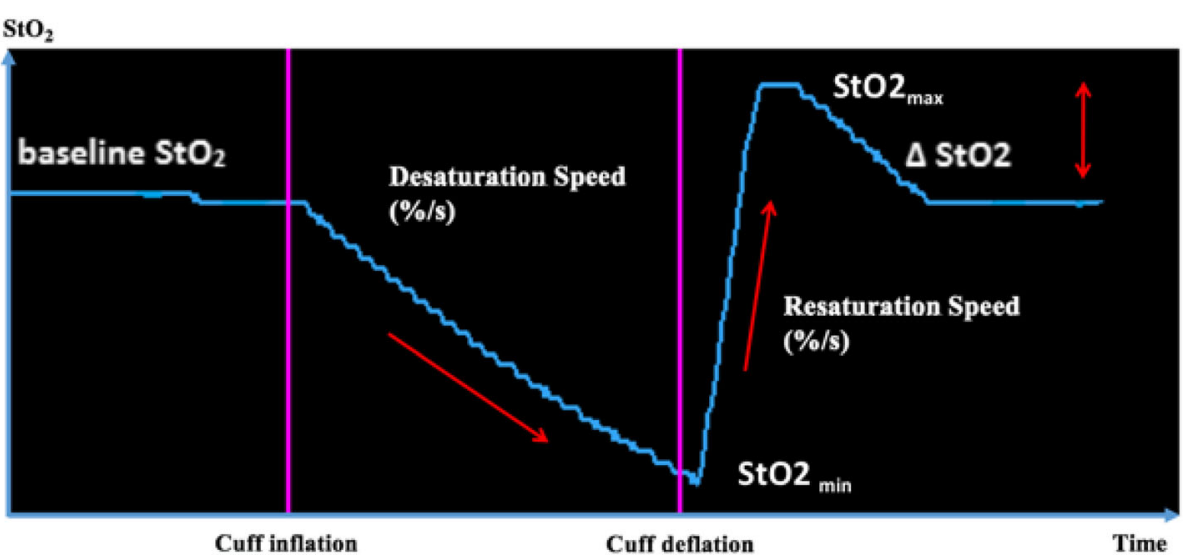

Fig. 1 Screen shot of a regular vascular occlusion test (VOT) measured with the $\mathrm{O} 3$ Regional oximetry device. Desaturation and resaturation speeds are expressed in \%/s. $\Delta \mathrm{StO}_{2}$ is calculated as $\mathrm{StO}_{2}$ max $-\mathrm{StO}_{2}$ baseline and expressed in \%. $\mathrm{StO}_{2}$ tissue oxygen saturation

\section{Study protocol}

For each included patient a complete set of measurements was carried out at the time of POAF, during esmolol infusion at incremental doses $(25 \mu \mathrm{g} / \mathrm{kg} / \mathrm{min}$ (E25), $50 \mu \mathrm{g} / \mathrm{kg} / \mathrm{min}$ (E50), $100 \mu \mathrm{g} / \mathrm{kg} / \mathrm{min}$ (E100), and $200 \mu \mathrm{g} / \mathrm{kg} / \mathrm{min}$ (E200)) to reach a targeted heart rate between 60 and 90 beats $/ \mathrm{min}$, and when the patient returned to sinus rhythm. As the half-life of esmolol is $9 \mathrm{~min}$, a stabilization period of $45 \mathrm{~min}$ was allowed between each dose. The whole study protocol is depicted in Fig. 2. Esmolol infusion was systematically stopped if the mean arterial pressure fell below $60 \mathrm{mmHg}$. According to best practice recommendations, no esmolol dose over $200 \mu \mathrm{g} / \mathrm{kg} / \mathrm{min}$ was used in the study.

\section{Endpoints}

The primary endpoint of the study was to assess the effects of POAF without hemodynamic instability on NIRS parameters in combination with a VOT. Secondary endpoints were to investigate the dose-dependent effects of intravenous esmolol on NIRS parameters in combination with a VOT in that specific setting.

\section{Statistical analysis}

The number of patients included in the pilot study was fixed empirically to 25 . Data are expressed as mean \pm SD, or median (range), or number (\%), according to their nature and distribution (Shapiro-Wilkinson test). We compared data during POAF and after a return to sinus rhythm by using a Wilcoxon test and/or a paired Student $t$ test, as appropriate. To estimate the effect of esmolol on the microcirculation, continuous variables were analyzed with a linear mixed model, using esmolol doses as a variable with a fixed effect, and patient as a variable with a random effect for intercepts and slopes. Visual inspection of residual plots was performed to assess the absence of deviations from homoscedasticity or normality $[25,26]$.

All tests were two-tailed, and a $P$ value less than 0.05 was considered statistically significant. Statistical analyses were performed using $R$ software version 3.2.5 (R-project, GNU GPL.) [27]. Several packages of Cran R project were used [28].

\section{Results}

Twenty-five patients were included (median age 63 (58-73) years old) in the study. Eighty-four percent underwent cardiac surgery and $16 \%$ underwent thoracic

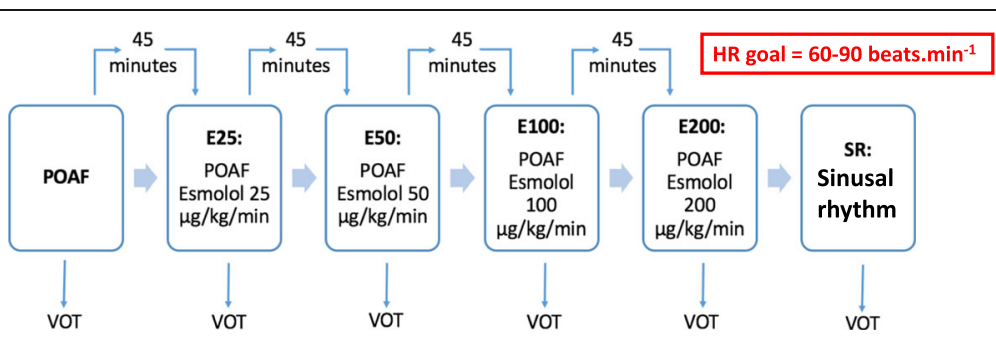

Fig. 2 Description of the study protocol. Each step lasted $45 \mathrm{~min}$ and the dose of esmolol was gradually increased to control ventricular heart rate (HR) between 60 and 90 beats/min. POAF postoperative atrial fibrillation. VOT vascular occlusion test 
surgery. The main characteristics of the patients are reported in Table 1. Four (16\%) patients required postoperative infusion of norepinephrine. Two patients did not return to sinus rhythm within the study period, of these one patient died and one patient was discharged with persistent POAF. One patient reached the targeted heart rate at E25, four patients at E50, and four patients at E100. Four patients did not reach the targeted heart rate at E200, and four patients returned to sinus rhythm during esmolol infusion. Seven patients developed arterial hypotension limiting the incremental dosage of esmolol.

Table 1 Demographic and clinical characteristics of the patients $(n=25)$

\begin{tabular}{|c|c|}
\hline Variable & Value \\
\hline Age (years) & $63(58-73)$ \\
\hline Sex ratio (male/female) & $16 / 9$ \\
\hline Body mass index $\left(\mathrm{kg} / \mathrm{m}^{2}\right)$ & $26(22-27)$ \\
\hline Euroscore 2 (\%) & $5(3-8)$ \\
\hline Left ventricular ejection fraction (\%) & $60(60-66)$ \\
\hline Preoperative serum creatinine $(\mu \mathrm{mol} / \mathrm{l})$ & $76(59-90)$ \\
\hline Glomerular filtration rate $\left(\mathrm{ml} / \mathrm{min} / 1.73 \mathrm{~m}^{2}\right)$ & $82(75-91)$ \\
\hline \multicolumn{2}{|l|}{ Comorbidities $(n, \%)$} \\
\hline Hypertension & $15(60)$ \\
\hline Chronic obstructive pulmonary disease & $2(8)$ \\
\hline Dyslipidemia & $11(45)$ \\
\hline Smokers & $6(24)$ \\
\hline \multicolumn{2}{|l|}{ Type of surgery $(n, \%)$} \\
\hline Coronary surgery & $8(32)$ \\
\hline Valve surgery & $12(48)$ \\
\hline Combined surgery & $2(8)$ \\
\hline Other cardiac surgery & $3(12)$ \\
\hline Thoracic surgery & $4(16)$ \\
\hline \multicolumn{2}{|l|}{ Chronic medications ( $n, \%)$} \\
\hline Beta blockers & $10(40)$ \\
\hline Renin angiotensin system inhibitors & $12(48)$ \\
\hline Statins & $11(44)$ \\
\hline Antiplatelet agents & $9(36)$ \\
\hline Calcium channel blockers & $5(20)$ \\
\hline Nitrates & $2(8)$ \\
\hline \multicolumn{2}{|l|}{ Vasoactive support } \\
\hline Norepinephrine at baseline ( $\mu \mathrm{g} / \mathrm{kg} / \mathrm{min})$ & $0.03 \pm 0.10$ \\
\hline \multicolumn{2}{|l|}{ During POAF } \\
\hline Kaliemia $(\mathrm{mmol} / \mathrm{l})$ & $4.1 \pm 0.4$ \\
\hline Hemoglobin (g/dl) & $10.8 \pm 1.6$ \\
\hline $\mathrm{SpO}_{2}(\%)$ & $96.0 \pm 1.8$ \\
\hline
\end{tabular}

Data are shown as median $\left(25^{\text {th }}-75^{\text {th }}\right.$ percentile), mean \pm SD, or number (\%) POAF postoperative atrial fibrillation, $\mathrm{SpO}_{2}$ arterial oxygen saturation
A significant decrease in heart rate was observed when POAF returned to sinus rhythm $(133 \pm 22$ beats/min versus $79 \pm 13$ beats $/ \mathrm{min}, P<0.001)$. The effects of POAF on hemodynamic and microcirculatory parameters are reported in Table 2. Baseline $\mathrm{StO}_{2}$ and resaturation speed significantly increased between POAF and return to sinus rhythm, while $\Delta \mathrm{StO}_{2}$ was significantly decreased (Table 2).

During esmolol infusion, heart rate, mean arterial pressure, and pulse pressure significantly decreased in a dose-dependent manner (Table 3 and Fig. 3). A nonsignificant trend toward an increase in both $\mathrm{StO}_{2}$ and resaturation speed was observed when incremental doses of esmolol were administered (Table 3 and Fig. 4).

\section{Discussion}

The main results of the current study conducted in cardiothoracic surgery patients are: 1 ) the microcirculation is impaired during POAF without hemodynamic instability and significantly improves following return to sinus rhythm within the first 7 postoperative days; 2) incremental doses of intravenous esmolol aiming to control ventricular heart rate between 60 and 90 beats/min trend to improve the microcirculation in a dose-dependent manner. As far as we know, this is the first study which evaluated the microcirculatory effects of POAF and the impact of esmolol infusion in this specific setting.

POAF can induce hemodynamic instability, significant hypotension, and a drop in cardiac output from roughly $30 \%$ [29]. After electrical cardioversion, stroke volume and cardiac output significantly increase [30, 31]. However, from a macrocirculatory point of view, POAF most often occurs without any hemodynamic instability.

Table 2 Hemodynamic and microcirculatory parameters during postoperative atrial fibrillation (POAF) and after return to sinus rhythm (SR)

\begin{tabular}{llll}
\hline Variables & POAF & SR & $P$ value \\
\hline Hemodynamic parameters & & & \\
$\mathrm{HR}($ beats/min) & $133 \pm 22$ & $79 \pm 13$ & $<0.001$ \\
$\mathrm{MAP}(\mathrm{mmHg})$ & $81 \pm 13$ & $80 \pm 13$ & 0.529 \\
$\mathrm{PP}(\mathrm{mmHg})$ & $49 \pm 12$ & $58 \pm 15$ & 0.041 \\
$\mathrm{SpO}_{2}(\%)$ & $95 \pm 2$ & $96 \pm 3$ & 0.944 \\
$\mathrm{Microcirculatory}$ parameters & & & \\
$\mathrm{StO}_{2}(\%)$ & $64 \pm 6$ & $67 \pm 6$ & $<0.001$ \\
Resaturation speed (\%/s) & $0.53(0.42-0.97)$ & $0.66(0.51-1.03)$ & 0.020 \\
$\mathrm{Desaturation}$ speed (\%/s) & $0.07(0.04-0.09)$ & $0.08(0.04-0.10)$ & 0.529 \\
$\Delta \mathrm{StO}_{2}$ (\%) & $7.9 \pm 4.8$ & $6.1 \pm 4.7$ & 0.026 \\
$\mathrm{StO}_{2}$ min (\%) & $40(40-49)$ & $40(40-49)$ & 0.396 \\
$\mathrm{StO}_{2}$ max (\%) & $72 \pm 5$ & $72 \pm 5$ & 0.483 \\
\hline Data & & &
\end{tabular}

Data are shown as absolute values, means $\pm S D$, or medians $\left(25^{\text {th }}-75^{\text {th }}\right.$ percentile)

$H R$ heart rate, MAP mean arterial pressure, $P P$ pulse pressure, $\mathrm{SpO}_{2}$ arterial oxygen saturation, $\mathrm{StO}_{2}$ tissue oxygen saturation 
Table 3 Hemodynamic and microcirculatory parameters during esmolol incremental dose regimen

\begin{tabular}{|c|c|c|c|c|c|c|}
\hline Variables & POAF & E25 & E50 & E100 & E200 & $P$ value \\
\hline \multicolumn{7}{|l|}{ Hemodynamic parameters } \\
\hline HR (beats/min) & $133(120-145)$ & $115(98-131)$ & $110(92-122)$ & 111.5(90-124) & $105(100-111)$ & $<0.001$ \\
\hline MAP (mmHg) & $84(71-89)$ & $71(64-85)$ & $73(62.0-78.5)$ & $69.5(62.7-78.2)$ & $66(63-69)$ & $<0.001$ \\
\hline $\mathrm{PP}(\mathrm{mmHg})$ & $51(40-59)$ & $44(30.5-53.0)$ & $41(28.5-46.0)$ & $42(32.7-49.2)$ & $45.5(35.0-53.5)$ & $<0.001$ \\
\hline $\mathrm{SpO}_{2}(\%)$ & 96 (94-98) & 96 (94-98) & 96 (94-98) & $96(95-98)$ & $96(95-98)$ & 0.787 \\
\hline \multicolumn{7}{|l|}{ Microcirculatory parameters } \\
\hline $\mathrm{StO}_{2}(\%)$ & $64(60-68)$ & $62.0(59.5-68.0)$ & $63.0(59.0-65.5)$ & $65.5(60.0-67.2)$ & $67.0(63.0-68.5)$ & 0.081 \\
\hline Resaturation speed (\%/s) & $0.53(0.42-0.97)$ & $0.61(0.44-0.95)$ & $0.74(0.45-0.96)$ & $0.88(0.47-1.03)$ & $0.82(0.54-1.14)$ & 0.087 \\
\hline Desaturation speed (\%/s) & $0.08(0.04-0.10)$ & $0.07(0.04-0.11)$ & $0.08(0.04-0.10)$ & $0.06(0.04-0.09)$ & $0.08(0.05-0.10)$ & 0.319 \\
\hline$\Delta \mathrm{StO}_{2}(\%)$ & $8(4-11)$ & $8(5.0-10.5)$ & $8(4-10)$ & $8.5(4.7-11.2)$ & $8.5(6-10.7)$ & 0.447 \\
\hline
\end{tabular}

Data are shown as medians $\left(25^{\text {th }}-75^{\text {th }}\right.$ percentile)

Esmolol infusion at incremental doses: $25 \mu \mathrm{g} / \mathrm{kg} / \mathrm{min}$ (E25), $50 \mu \mathrm{g} / \mathrm{kg} / \mathrm{min}$ (E50), $100 \mu \mathrm{g} / \mathrm{kg} / \mathrm{min}$ (E100), and $200 \mu \mathrm{g} / \mathrm{kg} / \mathrm{min}$ (E200) Continuous variables were analyzed with a linear mixed-effects model.

$H R$ heart rate, MAP mean arterial pressure, $P O A F$ postoperative atrial fibrillation, $P P$ pulse pressure, $\mathrm{SpO}_{2}$ arterial oxygen saturation, $\mathrm{StO}_{2}$ tissue oxygen saturation

Recently, Elbers et al. studied for the first time microcirculation during atrial fibrillation by using sidestream darkfield sublingual imaging [32]. They showed that a successful cardioversion significantly improved indices of sublingual microvascular perfusion. These results are in agreement with our findings. While no hemodynamic instability was evidenced in our patients, we found significant microcirculatory abnormalities suggesting a decrease in open capillaries during POAF that returned to a normal range when sinus rhythm was restored. Interestingly, Barrett et al. also used peripheral NIRS in combination with a VOT at the upper limb to assess microcirculation before and after electrical cardioversion in acute atrial fibrillation [33]. They suggested that changes were related to a reduction in open capillaries during atrial fibrillation, rather than intrinsic microcirculatory dysfunction.

Intravenous esmolol induces well-known hemodynamic effects on macrocirculatory parameters [34]. However, the effects on microcirculation are much less documented. In the present study, heart rate and blood pressure decreased in a dose-dependent manner when moving from 25 to $200 \mu \mathrm{g} / \mathrm{kg} / \mathrm{min}$ esmolol, whereas NIRS-derived microcirculation parameters, namely $\mathrm{StO}_{2}$ values and resaturation speed, trend to improve when incremental doses of esmolol were given. Previous reports have already suggested such a decoupling between the macro- and microcirculation in various clinical settings [35-37]. To date, the microcirculatory effects of esmolol have been mainly studied during sepsis. In that specific setting, a type 1 microcirculation alteration occurred which is characterized by heterogeneity in microcirculatory perfusion, with obstructed capillaries next to capillaries with flowing red blood cells [35]. In a porcine model of septic shock, Jacquet-Lagrèze et al. used gut and sublingual videomicroscopy and found that the sublingual microcirculation was unchanged during esmolol infusion despite simultaneous negative effects on the macrocirculation [22]. Furthermore, they observed a trend towards an improvement in gut microcirculation. In the current study, esmolol may similarly present positive effects on the microcirculation during POAF without hemodynamic instability. Intrinsic
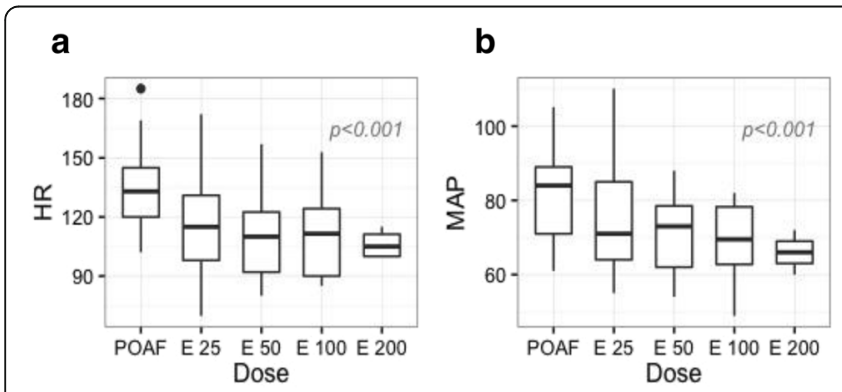

\section{C}

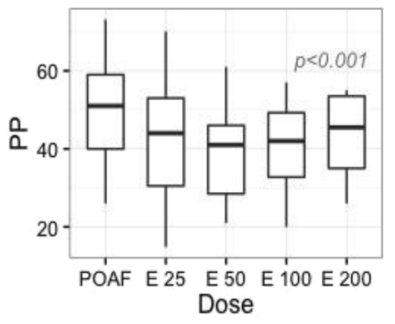

d

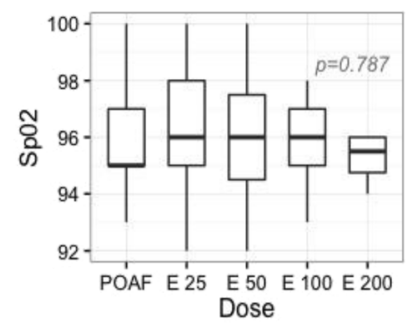

Fig. 3 Boxplots showing hemodynamic parameters. These parameters were obtained during postoperative atrial fibrillation (POAF) and incremental esmolol dose regimen (25 $\mathrm{gg} / \mathrm{kg} / \mathrm{min}$ (E25), $50 \mu \mathrm{g} / \mathrm{kg} / \mathrm{min}$ (E50), $100 \mu \mathrm{g} / \mathrm{kg} / \mathrm{min}$ (E100), and $200 \mu \mathrm{g} / \mathrm{kg} / \mathrm{min}$ (E200)). Continuous variables were analyzed with a linear mixed-effects model. a Heart rate (HR), (b) mean arterial pressure (MAP), (c) pulse pressure (PP), and (d) arterial oxygen saturation $\left(\mathrm{SpO}_{2}\right)$ 

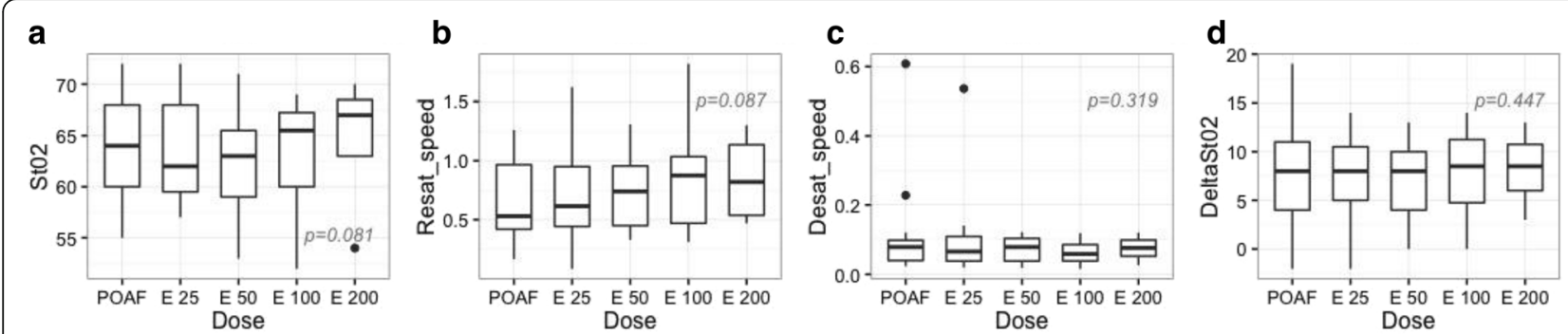

Fig. 4 Boxplots showing microcirculatory parameters. These parameters were obtained by NIRS in combination with a vascular occlusion test during postoperative atrial fibrillation (POAF) and during incremental esmolol dose regimen (25 $\mu \mathrm{g} / \mathrm{kg} / \mathrm{min}(E 25), 50 \mu \mathrm{g} / \mathrm{kg} / \mathrm{min}(E 50), 100 \mu \mathrm{gg} / \mathrm{kg} / \mathrm{min}(E 100)$, and $200 \mathrm{\mu g} / \mathrm{kg} / \mathrm{min}(E 200))$. Continuous variables were analyzed with a linear mixed-effects model. a Tissue oxygen saturation $\left(\mathrm{StO}_{2}\right)$, (b) resaturation speed, (c) desaturation speed, and (d) variation in $\mathrm{StO}_{2}$ during reperfusion (DeltaStO ${ }_{2}$ )

mechanisms remain unknown, however. The preservation and/or improvement in stroke volume by extending the diastolic filling time has been hypothesized [38]. A similar hypothesis was also supported in sepsis [39, 40]. Indeed, both sinus rhythm restoration and reduced heart rate increase the myocardial performance. Accordingly, it potentially improves stroke volume at the level of the smaller arterioles and at the precapillary sphincters, leading to an improvement in microcirculatory blood flow by recruitment of non-perfused capillaries. Furthermore, the microcirculation is well known for being highly responsive to inflammatory mediators; it induces impaired vasomotor function, leukocytes and platelets adhesion, and activation of the coagulation cascade with thrombosis. All these events lead to a reduction in functional capillaries. Esmolol has pleiotropic anti-inflammatory and immunosuppressive effects that decrease interleukin- 6 and tumor necrosis factor-alpha levels and might explain a possible positive effect on microcirculation.

Some comments are necessary regarding the limitations of the current study. First, we studied a specific subtype of surgical patients. Indeed, POAF is a specific entity with its own physiopathology [1]. Furthermore, a large majority of our patients had normal cardiac function and our results cannot be extrapolated to any other clinical situation, including patients with major cardiac dysfunction. Second, we only measured regional perfusion at the forearm level and we cannot extend our results to other regional microcirculations, such as the regulated cerebral one for instance. Further research should probably assess cerebral oximetry during POAF and esmolol infusion. In addition, the $\mathrm{O} 3$ device provides an accurate $\mathrm{StO}_{2}$ value with an absolute rootmean-squared error of $4 \%$, so that it is theoretically possible to compare absolute values [24]. Unfortunately, this device is not yet specifically designed for a peripheral microcirculation approach combining NIRS with a VOT [41]. Unlike sublingual videomicroscopy, NIRS combined with VOT is not a direct evaluation of the microcirculation. It is also crucial to take into account well-known limitations of peripheral NIRS monitoring $[42,43]$. NIRS tissue oxygen saturation is obtained from arteriolar, venular, and capillaries beds, without any adjustment regarding the contribution of each compartment. To determine $\mathrm{StO}_{2}$ we considered a ratio of $70 \%$ venous and $30 \%$ arterial, but major variation could occur [44]. A further limitation could be postoperative interstitial tissue edema acting as a confounding effect on $\mathrm{StO}_{2}$ values [45]. Third, Holter monitoring is the gold standard for POAF diagnosis. However, here, both POAF and return to sinus rhythm were diagnosed on a daily 12 lead-electrocardiogram in the surgical ward. Thus, we may have underestimated the true incidence of POAF and the spontaneous cardioversion rate, leading to a potential inclusion bias. Fourth, while all patients received fluid immediately before inclusion in the study, we no longer assess the volemic status of the patients within the study period. Subsequently, we cannot exclude that some patients experiencing hypotension (and in whom we stopped esmolol infusion) could have benefited from additional fluid administration. In those patients, the potential fluid-induced correction of mean arterial pressure could have modified results regarding the microcirculation. Fifth, it is impossible to identify a time-dependent effect on the microcirculation in the current protocol. Furthermore, it is important to differentiate spontaneous cardioversion from restoration of sinus rhythm during esmolol infusion because the use of a beta- 1 cardioselective beta blocker may change the microcirculatory pathophysiology. Finally, the number of patients we included was low and probably insufficient to show a significant statistical difference in resaturation speed and other microcirculation variables during esmolol dose ranging. Further studies including more surgical patients undergoing POAF are mandatory to eventually confirm our preliminary results. The upcoming availability of landiolol in Europe should also be an exciting way forward for this clinical research. 


\section{Conclusion}

POAF without hemodynamic instability is associated with a significant impairment in the microcirculation that improves with a return to sinus rhythm. The use of intravenous esmolol as a first-line therapy aiming to control ventricular heart rate tends to improve the microcirculation in a dose-dependent manner. Future studies are necessary to further assess the microcirculatory effects of esmolol and elucidate the underlying mechanisms.

\section{Abbreviations}

$\triangle S t O 2$ : Change in tissue oxygen saturation; NIRS: Near-infrared spectroscopy; POAF: Postoperative atrial fibrillation; $\mathrm{SpO}_{2}$ : Arterial oxygen saturation: $\mathrm{StO}_{2}$ : Tissue oxygen saturation; $\mathrm{StO}_{2}$ max: Maximum tissue oxygen saturation; $\mathrm{StO}_{2}$ min: Minimum tissue oxygen saturation; VOT: Vascular occlusion test

\section{Acknowledgements}

We thank Olivier Andremont for his help during Ethics approval. We thank Stanislas Ledochowski as well for the translation.

\section{Funding}

Department of Anesthesiology and Intensive Care, University Hospital Louis Pradel, Lyon, France.

\section{Availability of data and materials}

The dataset used and analyzed during the current study is available from the corresponding author on reasonable request.

\section{Authors' contributions}

WF wrote the article with the specific help and corrections of JLF. JLF designed the study and corrected the article. WF and TC acquired the data. MJL was responsible for the statistical analysis in cooperation with WF. All the authors read and approved the final manuscript.

\section{Ethics approval and consent to participate}

This study was approved by the Ethics Committee (A14-D06-VOL.20, 28/01/14 Comité de Protection des Personnes, Nord-Ouest 3; Committee Chair: Dr. Charlotte Gourio)

\section{Consent for publication}

Not applicable. The institutional review board waived written informed consent, as no intervention was required. Verbal information was, however, given to all patients.

\section{Competing interests}

JLF provides consulting for Baxter SAS France. The other authors declare that they have no competing interests.

\section{Publisher's Note}

Springer Nature remains neutral with regard to jurisdictional claims in published maps and institutional affiliations.

\section{Author details \\ ${ }^{1}$ Department of Anesthesiology and Intensive Care Medicine, University Hospital Louis Pradel, Lyon, France. ${ }^{2}$ Inserm U1060, IHU OPERA, Faculty of Medicine, Claude Bernard Lyon 1 University, Lyon, France. ${ }^{3}$ Cardiovascular Explorations, University Hospital Louis Pradel, Lyon, France. ${ }^{4} 12$ rue Vaubecour, Lyon 69002, France.}

Received: 7 July 2017 Accepted: 13 November 2017 Published online: 12 December 2017

\section{References}

1. Maesen B, Nijs J, Maesen J, Allessie M, Schotten U. Post-operative atria fibrillation: a maze of mechanisms. Eurospace. 2012;14:159-74.

2. Chelazzi C, Villa G, De Gaudio AR. Postoperative atrial fibrillation. ISRN Cardiol. 2011;2011:203179.
3. Almassi GH, Schowalter T, Nicolosi AC, et al. Atrial fibrillation after cardiac surgery: a major morbid event? Ann Surg. 1997;226(4):501-11.

4. Kirchhof P, Benussi S, Kotecha D, et al. 2016 ESC Guidelines for the management of atrial fibrillation developed in collaboration with EACTS. Eur Heart J. 2016;37(38):2893-962.

5. Gorczynski RJ. Basic pharmacology of esmolol. Am J Cardiol. 1985;56:3F-13F

6. Askenazi J, MacCosbe PE, Hoff J, Turlapaty P, Hua TA, Laddu A. Hemodynamic effects of esmolol, an ultrashort-acting beta blocker. J Clin Pharmacol. 1987;27(8):567-73.

7. Gomez H, Torres A, Polanco P, et al. Use of non-invasive NIRS during a vascular occlusion test to assess dynamic tissue $\mathrm{O} 2$ saturation response. Intensive Care Med. 2008;34(9):1600-7.

8. Zamparini G, Butin G, Fischer MO, Gérard JL, Hanouz JL, Fellahi JL. Noninvasive assessment of peripheral microcirculation by near-infrared spectroscopy: a comparative study in healthy smoking and nonsmoking volunteers. J Clin Monit Comput. 2015;29(5):555-9.

9. Fellahi JL, Butin G, Zamparini G, Fischer MO, Gérard JL, Hanouz JL. Lower limb peripheral NIRS parameters during a vascular occlusion test: an experimental study in healthy volunteers. Ann Fr Anesth Reanim. 2014;33(1):e9-e14.

10. Lipcsey M, Woinarski NC, Bellomo R. Near infrared spectroscopy (NIRS) of the thenar eminence in anesthesia and intensive care. Annals of Intensive Care. 2012;2:11.

11. Ferraris $A$, Jacquet-Lagrèze $M$, Fellahi JL. Four-wavelength near-infrared peripheral oximetry in cardiac surgery patients: a comparison between EQUANOX and O3. J Clin Monit Comput. 2017. doi:10.1007/s10877-0170025-Z.

12. Fellahi JL, Butin G, Fischer MO, Zamparini G, Gérard JL, Hanouz JL. Dynamic evaluation of near-infrared peripheral oximetry in healthy volunteers: a comparison between INVOS and EQUANOX. J Crit Care. 2013;28(5):881.e1-6.

13. Futier E, Christophe S, Robin E, et al. Use of near-infrared spectroscopy during a vascular occlusion test to assess the microcirculatory response during fluid challenge. Crit Care. 2011;15:R214

14. Fischer MO, Fellahi JL, Hanouz JL, et al. French Hemodynamic Team. Assessment of macro- and micro-oxygenation parameters during fractional fluid infusion: a pilot study. J Crit Care. 2017;40:91-8.

15. Monthé-Sagan K, Fischer MO, Saplacan V, Gerard JL, Hanouz JL, Fellahi JL. Near-infrared spectroscopy to assess microvascular dysfunction: a prospective pilot study in cardiac surgery patients. J Crit Care. 2016;31(1):264-8.

16. Fellahi $J$, Fischer MO, Rebet $O$, Dalbera A, Massetti M, Gérard $J$, Hanouz $J$. Cerebral and somatic near-infrared spectroscopy measurements during fluid challenge in cardiac surgery patients: a descriptive pilot study. J Cardiothorac Vasc Anesth. 2013;27(2):266-72.

17. Bouchet JB, Durand E, Morel J, et al. Microcirculatory dysfunction after cardiac surgery: interest of NIRS technology with two case reports. Ann Fr Anesth Reanim. 2011;30(7-8):589-93.

18. Duret J, Pottecher J, Bouzat $P$, et al. Skeletal muscle oxygenation in severe trauma patients during haemorrhagic shock resuscitation. Crit Care. 2015;19:141.

19. Creteur J, Carollo T, Soldati G, Buchele G, De Backer D, Vincent JL. The prognostic value of muscle $\mathrm{StO} 2$ in septic patients. Intensive Care Med. 2007;33(9):1549-56.

20. Macdonald SP, Brown SG. Near-infrared spectroscopy in the assessment of suspected sepsis in the emergency department. Emerg Med J. 2015;32(5): 404-8.

21. Soga T, Sakatani K, Yagi T, Kawamorita T, Yoshino A. The relationship between hyperlactatemia and microcirculation in the thenar eminence as measured using near-infrared spectroscopy in patients with sepsis. Emerg Med J. 2014;31(8):654-8.

22. Jacquet-Lagrèze $M$, Allaouchiche $B$, Restagno $D$, et al. Gut and sublingual microvascular effect of esmolol during septic shock in a porcine model. Crit Care. 2015;19(1):241.

23. Morelli A, Donati A, Ertmer C, Rehberg S. Microvascular effects of heart rate control with esmolol in patients with septic shock: a pilot study. Crit Care Med. 2013;41(9):2162-8

24. Redford D, Paidy S, Kashif F. absolute and trend accuracy of a new regional oximeter in healthy volunteers during controlled hypoxia. Anesth Analg. 2014;119(6):1315-9.

25. Bates D, Maechler M, Bolker B, Walker S. Fitting linear mixed-effects models using Ime4. J Stat Softw. 2015;67(1):1-48.

26. Pinheiro J, Bates D, DebRoy S, Sarkar D and R Core Team. nlme: Linear and nonlinear mixed effects models. 2017; R package version 3.1-131. https://CRAN.R-project.org/package=nlme. Accessed 6 Feb 2017. 
27. R Development Core Team. R: A language and environment for statistical computing. Vienna, Austria: R Foundation for Statistical Computing. 2008. http://www.r-project.org. Accessed 11 June 2015.

28. Olkin I, Finn JD. Correlations redux. Psychol Bull. 1995;118:155-64.

29. Halmos B, Patterson GC. Effect of atrial fibrillation on cardiac output. Br Heart J. 1965;27(5):719-23.

30. Giglioli C, et al. Hemodynamic effects in patients with atrial fibrillation submitted to electrical cardioversion. Int J Cardiol. 2013;168(4):4447-50.

31. Storstein $\mathrm{O}$, Tveten $\mathrm{H}$. The hemodynamic effect of restoring normal sinus rhythm in patients with auricular fibrillation. Scand J Clin Lab Invest. 1955; 7(2):167-70.

32. Elbers $\mathrm{P}$, Prins $\mathrm{W}$, Plokker $\mathrm{H}$, et al. Electrical cardioversion for atrial fibrillation improves microvascular flow, independent of blood pressure changes. J Cardiothorac Vasc Anesth. 2012;26(5):799-803.

33. Barrett OS, Macdonald SP, Playford DA. Near-infrared spectroscopy-based microcirculatory assessment in acute atrial fibrillation. Anaesth Intensive Care. 2015;43(1):105-10.

34. Yu SK, Tait G, Karkouti K, Wijeysundera D, McCluskey S, Beattie WS. The safety of perioperative esmolol: a systematic review and meta-analysis of randomized controlled trials. Anesth Analg. 2011;112(2):267-81.

35. Ince $\mathrm{C}$. Hemodynamic coherence and the rationale for monitoring the microcirculation. Crit Care. 2015;19(3):S8.

36. Arnold R, Dellinger R, Parrillo J, et al. Discordance between microcirculatory alterations and arterial pressure in patients with hemodynamic instability. J Crit Care. 2012;27(531):e1-7.

37. Dubin A, Pozo O, Casabell C, et al. Increasing arterial blood pressure with norepinephrine does not improve microcirculatory blood flow: a prospective study. Crit Care. 2009;13:R92.

38. Ince C. To beta block or not to beta block; that is the question. Crit Care 2015;19:339

39. Aboab J, Sebille $V$, Jourdain $M$, et al. Effects of esmolol on systemic and pulmonary hemodynamics and on oxygenation in pigs with hypodynamic endotoxin shock. Intensive Care Med. 2011;37:1344-51.

40. Morelli A, Ertmer C, Westphal M, et al. Effect of heart rate control with esmolol on hemodynamic and clinical outcomes in patients with septic shock: a randomized clinical trial. JAMA. 2013;310:1683-91.

41. Lipcsey M, Eastwood GM, Woinarski NC, Bellomo R. Near-infrared spectroscopy of the thenar eminence: comparison of dynamic testing protocols. Crit Care Resusc. 2012:14(2):142-7.

42. Messere A, Roatta S. Local and remote thermoregulatory changes affect NIRS measurement in forearm muscles. Eur J Appl Physiol. 2015;115(11):2281-91.

43. Ferrari M, Mottola L, Quaresima V. Principles, techniques, and limitations of near infrared spectroscopy. Can J Appl Physiol. 2004;29(4):463-87.

44. Watzman H, Kurth CD, Montenegro LM, Rome J, Steven JM, Nicolson SC. Arterial and venous contributions to near-infrared cerebral oximetry. Anesthesiology. 2000;93(4):947-53.

45. Poeze M. Tissue oxygenation assessment using near-infrared spectroscopy during severe sepsis: confounding effects of tissue edema on $\mathrm{StO} 2$ values. Intensive Care Med. 2006;32(5):788-9.

\section{Submit your next manuscript to BioMed Central and we will help you at every step:}

- We accept pre-submission inquiries

- Our selector tool helps you to find the most relevant journal

- We provide round the clock customer support

- Convenient online submission

- Thorough peer review

- Inclusion in PubMed and all major indexing services

- Maximum visibility for your research

Submit your manuscript at www.biomedcentral.com/submit

) Biomed Central 